\title{
Género y economía. Visibilización de la contribución de las mujeres en la agricultura familiar campesina en Paraguay. Año 2019
}

\section{Gender and economy. Visibility of the contribution of women in peasant family agriculture in Paraguay. Year 2019}

\author{
Dahiana Ayala ${ }^{\oplus}$, Marcela Achinelli $^{2} \oplus$
}

\begin{abstract}
Resumen
El artículo tiene como objetivo visibilizar la contribución de las mujeres en la agricultura familiar campesina y profundizar en la posibilidad que tienen las mismas, para acceder a la tierra, al crédito y a la tecnología, elementos generadores de desarrollo agrícola y por qué no, potenciadores de la autonomía económica de las productoras. Según (Kempf et al., 2019), las relaciones sociales y de producción presentes en la agricultura familiar campesina presentan contextos peculiares con relación a otros tipos de modelos de agricultura, uno de ellos, se refiere al trabajo de las mujeres y la magnitud de su contribución laboral en el establecimiento familiar, además de ser el pilar fundamental en la promoción de la seguridad alimentaria. La contribución económica y social de las mujeres en la agricultura familiar debe ser visibilizada y sujeta de políticas públicas para fomentar la igualdad de género en el contexto rural, significando esto, la generación de canales de participación de las mujeres en todo el desarrollo de la cadena de valor de la producción, impulsando el reconocimiento de las mujeres como actoras principales en la sostenibilidad del modelo agro-familiar y la soberanía alimentaria. En cuanto a la metodología, esta se desarrolla a partir de un análisis de la información cuantitativa, para lo cual se hizo uso de los datos secundarios proveídos por el Ministerio de Agricultura y Ganadería a través de la Dirección de Extensión Agraria (DEAg) con todos los programas que intervienen en la Agricultura Familiar y el Instituto Nacional de Estadística (DGEEC) con la Encuesta Permanente de Hogares (EPH) y la Encuesta de Uso del Tiempo (EUT), considerando para la Encuesta de Hogares una temporalidad de 10 años y, para el caso de la encuesta de uso del tiempo correspondiente al año 2016, así como el Censo Agropecuario Nacional (CAN) del año 2008. Entre los principales resultados se puede observar que las mujeres rurales padecen más fuertemente la pobreza, el 23,0\% de ellas se encuenta en situación de pobreza y el $8,7 \%$ en condición de pobreza extrema, el $24 \%$ de las mujeres rurales trabaja como trabajadoras familiares sin percibir salario alguno, cuando se trata de explotación agropecuaria las mujeres se encuentran en mayor desventaja que los hombres, en el estrato de menos de una hectárea ellas representan
\end{abstract}

\author{
1 Aix Marseille Université, \\ Francia. \\ 2 Universidad Nacional de \\ Asunción, Facultad de Ciencias \\ Económicas. San Lorenzo, \\ Paraguay. \\ Correspondencia: \\ dahianaayala288@gmail.com \\ Recibido: \\ 16 de junio de 2021 \\ Aceptado: \\ 4 de octubre de 2021 \\ Doi: \\ https://doi.org/10.54549/ky.6e.2021.11
}


el $36 \%$ de los productores, mientras que su participación se reduce al $15 \%$ en las de más de 1.000 hectáreas. El 44\% de las mujeres inactivas rurales señala como razón principal el realizar labores del hogar, lo que concuerda con la mayor carga de trabajos no remunerados que ellas deben soportar, lo que significa mayores problemas de inserción al mercado laboral, mayor informalidad laboral y por ende la imposibilidad de desarrollar una vida plena, esto aunado a la poca participación que ellas tienen en los proyectos productivos y de financiamiento desarrollados por el gobierno y el casi nulo acceso a la propiedad de la tierra.

Palabras clave: agricultura familiar, contribución, mujeres, visibilización.

\begin{abstract}
The article analyzes the contribution of women in family farming and delves into the possibility that women have to access land, credit and technology, elements that generate agricultural development and why not, enhancers of the economic autonomy of the producers. The social and production relations present in peasant family agriculture present peculiar contexts in relation to other types of agricultural models, one of them refers to the work of women and the magnitude of their labor contribution in the family establishment, in addition to be the fundamental pillar in the promotion of food security. The economic and social contribution of women in family farming should be made visible and subject to public policies to promote gender equality in the rural context, meaning the generation of channels for the participation of women throughout the development of the chain. value of production, promoting the recognition of women as main actors in the sustainability of the agro-family model and food sovereignty. Regarding the methodology, it is developed from an analysis of quantitative information, for which use was made of the data provided by the Ministry of Agriculture and Livestock through the Directorate of Agrarian Extension (DEAg) with all the programs that intervene in Family Farming and the National Statistics Institute (DGEEC) with the Permanent Household Survey (EPH) and the Time Use Survey (EUT), considering for the Household Survey a temporality of 10 years and, for the case of the time use survey corresponding to the year 2016, as well as the National Agricultural Census (CAN) of the year 2008. Among the main results, it can be observed that rural women suffer more strongly from poverty, $23.0 \%$ of them are in poverty and $8.7 \%$ in extreme poverty, $24 \%$ of rural women work As family workers without receiving any salary, when it comes to agricultural exploitation, women are at a greater disadvantage than men, in the stratum of less than one hectare they represent $36 \%$ of the producers, while their participation is reduced to $15 \%$ in those with more than 1,ooo hectares. $44 \%$ of inactive rural women indicate as the main reason to perform housework, which is consistent with the greater burden of unpaid work that they must endure, which means greater problems of insertion into the labor market, greater labor informality and, hence the impossibility of developing a full life, this coupled with the little participation that they have in the productive and financing projects developed by the government and the almost zero access to land ownership.
\end{abstract}

Keywords: family farming, contribution, women, visibility.

\title{
1. Introducción
}

Paraguay es un país basado en el modelo agroexportador, cuyos productos principales (soja y carne) ocupan el cuarto y sexto lugar en exportaciones a nivel mundial (Carosini et al., 2020). Sin embargo, este tipo de economía se traduce en desigualdad, debido a que el crecimiento económico se desarrolla desconectado del entorno, siendo la explotación (de recursos humanos y naturales) una constante, generando vulnerabilidad en los trabajadores y trabajadoras, así como en el ecosistema (Centro Latinoamericano para el Desarrollo Rural [RIMISP], 2015).

De acuerdo con los datos de la Comisión Económica para América Latina y 
el Caribe (CEPAL), en Paraguay una de cada dos personas vive en la pobreza, y una de cada tres personas en la pobreza extrema. Si analizamos la pobreza de acuerdo a la zona geográfica, es la zona rural la más afectada y si desagregamos por sexo, son las mujeres quienes más la padecen (Campos, 2016).

Si bien los indicadores de desarrollo humano y desigualdad de género reflejan mejoría en los últimos años, a partir de políticas enfocadas en educación y salud (PNUD, 2010), la multicausalidad de la pobreza en lo referente al acceso a los recursos, principalmente la tierra para las mujeres rurales sigue apuntando a Paraguay como uno de los países más rezagados en desarrollo humano (Campos, 2016).

Más de un millón de mujeres viven en la zona rural, sosteniendo hogares con sus trabajos tanto al interior de los hogares como en las comunidades, manejando la siembra, extrayendo el agua de pozo y leña, procesando harina, lácteos, eso y más sin añadir el cuidado de personas y animales domésticos y de granja (Guereña, 2016).

Las mujeres rurales son altamente dependientes de la agricultura familiar (AF), por lo tanto, son consideradas una pieza fundamental en el sector, vinculadas de manera estratégica en el objetivo global de la erradicación del hambre y el cambio hacia sistemas agrícolas más sostenibles, sin embargo, son quienes terminan explotadas, invisibles en las estadísticas nacionales a pesar de su contribución a la producción agropecuaria del país (Guereña, 2016).

El artículo tiene como objetivo visibilizar la contribución de las mujeres en la agricultura familiar campesina, considerando un conjunto de informaciones que ponen sobre la lupa su aporte no solo al desarrollo de la agricultura familiar en sí, sino al desarrollo de su vida en el contexto rural, el artículo se centra en mostrar información sobre sus características laborales, el trabajo dentro del hogar, la carga de trabajo de cuidados y la imposibilidad de conciliar la vida productiva y reproductiva, factores que generan distorsiones en el mercado de trabajo, incorporado a eso la imposibilidad que tienen las mujeres campesinas de ser dueñas de su propia tierra, del acceso a programas de financiamiento, que sin duda imposibilitan una vida plena y autónoma.

La metodología prevista consiste en el análisis de datos secundarios provenientes del Censo Agropecuario Nacional (CAN) desarrollado en el año 20o8, y la encuesta permanente de hogares (EPH) del año 2018. El análisis cuantitativo, consistente en la descripción de frecuenciasy porcentajes que permiten visibilizar el aporte de las mujeres en el entorno de la agricultura familiar, considerando aspectos sociodemográficos y económicos para el año 2018, así como datos de la participación de ellas dentro de los programas de desarrollo productivo proveniente del Ministerio de Agricultura y Ganadería (MAG).

De acuerdo a la Ley $\mathrm{N}^{\circ}$ 2419/2004, la AF en Paraguay se define como aquella en la cual el recurso básico de la mano de obra lo aporta el grupo familiar, siendo su producción básicamente de autoconsumo y parcialmente mercantil, complementando los ingresos a partir de otras producciones de carácter artesanal o extrapredial.

De acuerdo a dicha ley, la agricultura familiar tiene algunas particularidades que se citan a continuación: 1) La mano de obra ocupada en la finca corresponderá predominantemente a la familia, siendo limitada la ocupación de trabajadores contratados; 2) La familia es responsable directa de la producción y gestión de la actividad agrícola, ganadera y/o forestal, y deberá residir en la propia finca o en una localidad próxima, y necesariamente los ingresos deberán proceder de la producción del lote agrícola 3) Los recursos productivos utilizados serán compatibles con la capacidad de trabajo de la familia, con la actividad desarrollada y con la tecnología utilizada. 4) Son parte de la Agricultura Familiar, respetando los demás criterios, los productores rurales sin tierra propia, los beneficiarios de la reforma agraria o programas de acceso y permanencia en la tierra, así como de otras políticas fundiarias, 
Figura 1. Participación de la agricultura familiar (AF) y de los medianos y grandes productores (MGP), en las fincas y en superficie total (\%)

\section{Participación en la cantidad de fincas}

\section{Participación en la superficie total}
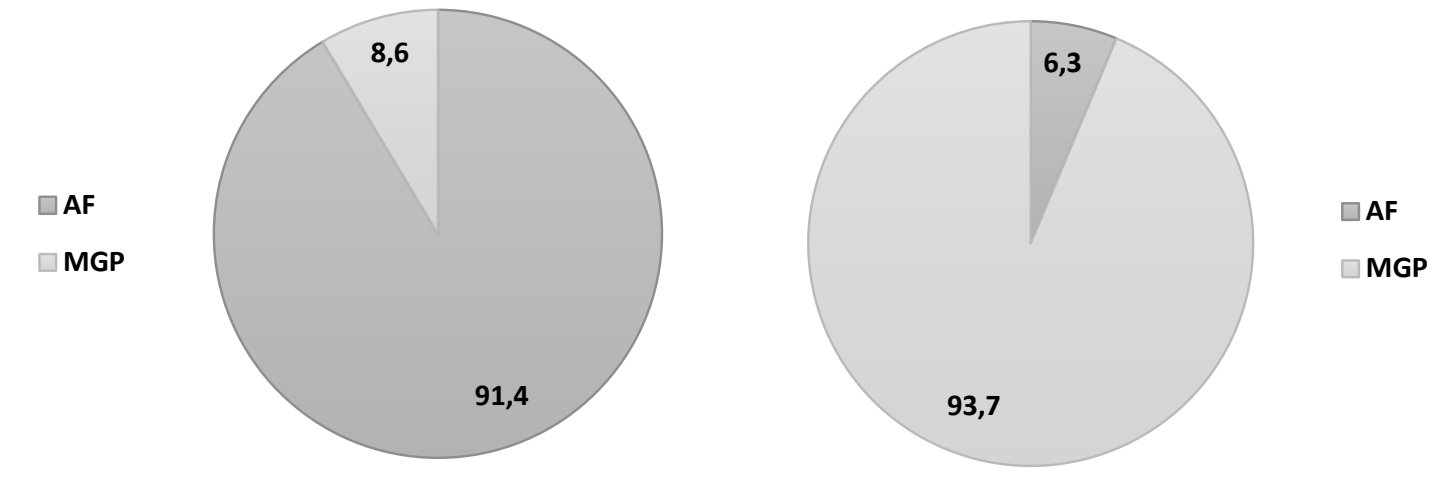

Fuente: Elaboración propia en base a datos del Censo Agropecuario Nacional (MAG, 2008).

como de las comunidades de productores y/o indígenas que hacen uso común de la tierra.

Entre algunos resultados se puede observar que las mujeres rurales padecen más fuertemente la pobreza, el 23,0\% de ellas se encuenta en situación de pobreza y el $8,7 \%$ en condición de pobreza extrema, el $24,0 \%$ de las mujeres rurales trabaja como trabajadoras familiares sin percibir salario alguno, cuando se trata de explotación agropecuaria las mujeres se encuentran en mayor desventaja que los hombres, en el estrato de menos de una hectárea ellas representan el 36,0\% de los productores, mientras que su participación se reduce al $15,0 \%$ en las de más de 1.000 hectáreas. El $44 \%$ de las mujeres inactivas rurales señala como razón principal el realizar labores del hogar, lo que concuerda con la mayor carga de trabajos no remunerados que ellas deben soportar, lo que significa mayores problemas de inserción al mercado laboral, mayor informalidad laboral y por ende la imposibilidad de desarrollar una vida plena, esto aunado a la poca participación que ellas tienen en los proyectos productivos y de financiamiento desarrollados por el gobierno y el casi nulo acceso a la propiedad de la tierra.

En materia de programas de políticas públicas para el fomento de la AF, el Ministerio de Agricultura y Ganadería cuenta con diversos programas que tienen como objetivo generar las condiciones para que los pequeños productores de la AF puedan acceder a servicios institucionales que le permitan la producción familiar de alimentos, promover el crecimiento de la producción agropecuaria, fortalecer la capacidad asociativa de los pequeños productores, fomento de la integración de organizaciones rurales a las cadenas de valor y la sostenibilidad de este modelo de producción.

\section{El problema de acceso a la tierra de las poblaciones vulnerables}

En Paraguay, la tenencia de la tierra es uno de los principales factores de la desigualdad y de pobreza, la estructura de su tenencia se traduce en uno de los más elevados índices de desigualdad social en las zonas rurales. De acuerdo con los datos del censo agropecuario nacional de 
Figura 2. Índice de gini en concentración de la tierra

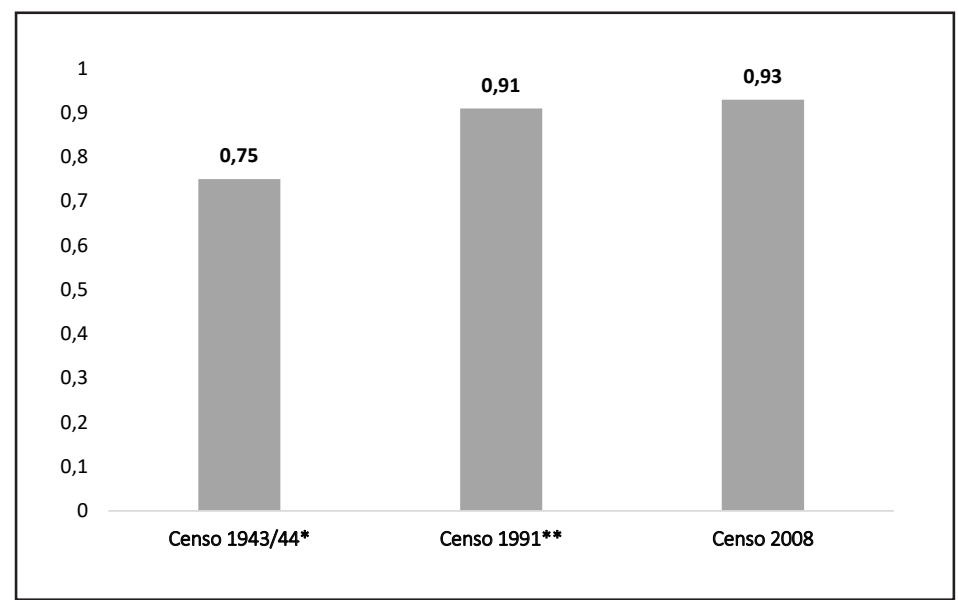

Fuente: Tomado del documento de Seguridad y soberanía alimentaria en Paraguay (Imaás et al., 2019). Nota: *El valor del índice hubiese sido mucho mayor si se hubiesen incluido algunos de los grandes latifundios históricos, que fueron excluidos de ese primer censo por no dedicarse a la agricultura sino a la ganadería o a actividades extractivas. ${ }^{* *}$ Después del censo de 1943-44 cuando se incorporaron las explotaciones ganaderas, los niveles de concentración de las tierras resultaron superiores a los arrojados por aquel primer relevamiento censal.

2008 (MAG, 2008), los medianos y grandes productores (MGP) representan el 7,3\% del total de personas dedicadas a la actividad agropecuaria'. El sector productivo rural de Paraguay muestra un dualismo en cuanto a la diferencia de activos, recursos, ocupación y capital humano. Una primera comparación permite observar el peso de las fincas de menos de 50 hectáreas $(91,4 \%)$ sobre el total de fincas, que sin embargo cuentan con un $6,3 \%$ de la superficie total de tierras censadas. Por otra parte, los Medianos y Grandes Productores (MGP) representan el $8,6 \%$ de las fincas y el $93,7 \%$ de la superficie (Figura 1).

La falta de acceso a la tierra afecta principalmente a la población campesina e indígena, y al mismo tiempo incide de

1 No existe un acuerdo pleno para definir las categorías operacionales que sirven para distinguir a los productores medianos y grandes de los productores dedicados a la agricultura familiar. En este caso, se considera productores grandes y medianos a aquellos que cuentan con 50 o más hectáreas y productores de la agricultura familiar a los que tienen menos de 50 hectáreas (PNUD, 2010). manera diferenciada y más profunda en ciertos segmentos de la población, es el caso de campesinos y campesinas jóvenes. La concentración de tierras en manos de grandes productores, la fragilidad de la pequeña economía campesina y la propia dinámica de crecimiento de las familias son factores que limitan sus oportunidades para acceder a parcelas propias (Kretschmer, 2008). Cuando las personas jóvenes quieren independizarse $y$ formar una familia, encuentran que no tienen tierras $y$ en muchas ocasiones se ven forzadas a permanecer en el lote paterno. Una parte significativa de la población juvenil de las áreas rurales, así, pasa a engrosar el número de migrantes o de campesinos y campesinas sin tierras (Dobrée, 2014).

Según Guereña (2016), en un contexto de grandes desigualdades en el acceso a la tierra en las zonas rurales, la vulnerabilidad de la población rural se acentúa, ya que este recurso es esencial como medio de producción y de desarrollo, esta situación de grandes diferencias en el reparto de la tierra hace que la población 
campesina-joven en su gran mayoría se inserte en empleos informales, temporales profundizando la situación de pobreza y desigualdad.

El Îndice de Gini en concentración de tierra, se ha elevado de 0,91 en 1991 a o,93 en el 2008, lo que indica que el valor del año 2008 se va aproximando al valor 1 de máxima desigualdad. De hecho, la concentración de la tierra en Paraguay es la mayor de América Latina y considerada como una de las peores del mundo, desde el momento en que el índice de Gini muestra casi como una desigualdad absoluta (Imás et al., 2019) (Figura 2).

\subsection{Supervivencia de la agricultura familiar}

El principal obstáculo que presenta la AF es la poca vinculación de los agricultores a pequeña escala con los mercados locales e internacionales, la informalidad de los pequeños productores rurales, los efectos del cambio climático en la producción y la falta de inversión direccionada a este sector, en términos más concretos la supervivencia de la AF, en un contexto de crecimiento agro-exportador excluyente, se ve amenazada también por la escasa financiación, la regresividad e injusticia del sistema tributario y por ende, la exigua articulación de la política fiscal (impuestos y gastos) con otros aspectos fundamentales para el desarrollo integral de la pequeña agricultura familiar, en este contexto de desventaja, las mujeres se encuentran fuertemente vulnerabilizadas por el hecho de que producen en un contexto de mayor inseguridad y desigualdad en el acceso a la tierra, a la obtención de créditos para la producción y tecnología para el mejoramiento de sus productos (FAO, 2008; FAO 2013).

La AF es altamente responsable de la producción de una decena de cultivos como el poroto y la mandioca ( $94 \%$ de la producción nacional), la batata $(89,6 \%)$ y de frutas, en gran medida. Se trata de rubros

Tabla 1. Participación de la Agricultura Familiar en la producción total (\%)

\begin{tabular}{ccc}
\hline Rubros & \% de Producción AF & $\begin{array}{c}\text { \% de Producción } \\
\text { MGP }\end{array}$ \\
\hline Poroto & 93,9 & \\
Mandioca & 93,6 & \\
Ka'a he'ê & 93,6 & \\
Tabaco & 93,1 & \\
Tártago & 91,6 & \\
Algodón & 89,7 & \\
Batata & 89,6 & \\
Sésamo & 88,9 & \\
Menta & 87,8 & \\
Caña de Azúcar & 52,6 & 47,4 \\
Maní & 37,5 & 62,5 \\
Maíz & & 83,3 \\
Trigo & & 92,7 \\
Canola & & 92,8 \\
Soja & & 93,9 \\
Girasol & & 96,1 \\
Arroz c/riego & & 96,8 \\
\hline
\end{tabular}

Fuente: Elaboración propia en base a datos del Censo Agropecuario Nacional (MAG, 2008). 
en general perecibles, cuya mecanización es inviable, que demandan intensa mano de obra; y que son aptos no sólo para renta sino también para el consumo de las familias productoras. La AF desempeña además un papel relevante en la seguridad y soberanía alimentaria, conserva el germoplasma (variabilidad genética que puede perpetuar una especie) nativo de especies como el maní jhuí, avatí carapé pyta, zapallo cururú, poroto San Francisco y produce rubros de renta estratégicos (sésamo, ka'a he'ê, cedrón, etc.) para el ingreso de divisas (PNUD, 2010) (Tabla 1).

La agricultura empresarial es responsable de la casi totalidad de la producción de la soja, el maíz, el trigo, el girasol y el arroz, cultivados y cosechados en forma mecánica y con uso intensivo de bienes de capital e insumos químicos. En la producción del maní y la caña de azúcar de uso industrial, ambos grupos -el de la AF y los productores empresariales- comparten su participación de forma más equilibrada .

\subsection{Agricultura familiar $y$ participación femenina}

El primer estudio relevante sobre la participación femenina en el sector agropecuario de América Latina fue el realizado por Boserup (1970). A partir de un análisis de los sistemas agrarios regionales en los países del Tercer Mundo, Boserup clasifica a la agricultura latinoamericana como un "sistema agrario masculino", en el que la producción de alimentos es llevada a cabo fundamentalmente por los hombres, en contraposición a la agricultura africana, que la califica de "sistema agrario femenino". Posteriores estudios criticarán esta postura, entre ellos los de Benería y Sen (1981) que argumentan en contra del determinismo tecnológico que implica la postura de Boserup, ya que asocia la agricultura femenina con la azada y la masculina con el advenimiento del arado, y contra su falta de inclusión de las clases sociales en el análisis. Señalan además que Boserup acepta el modelo capitalista de desarrollo como algo dado, y que no incorpora el papel que juega la mujer en la reproducción de la fuerza de trabajo.

Deere y León de Leal (1982), en una investigación realizada sobre las mujeres en la agricultura andina, señalan que en América Latina todavía es regla un cierto grado de subordinación femenina, más allá del aumento en la participación de la mujer en el mercado laboral. En su trabajo definen una nueva categoría que denominan "el sistema agrario de familia patriarcal", en el que tanto los hombres como las mujeres aportan fuerza de trabajo, pero son los hombres quienes controlan el poder de decisión y el resultado de la producción. Estas investigadoras continuaron trabajando en la caracterización de los roles que asumen las mujeres en la agricultura campesina de América Latina.

En la década de los 1980os se desarrolló una serie de estudios de caso que proporcionaron evidencia empírica sobre el rol significativo que desempeñaban las mujeres en la producción de las unidades agropecuarias familiares, pero los datos obtenidos no eran comparables entre sí y se carecía de información regional que permitiera comparar las características y tendencias de la participación de mujeres en la pequeña producción agropecuaria.

Los informes del Centro Latinoamericano para el Desarrollo Rural (RIMISP) muestran una desigualdad significativa en Latinoamérica, donde las diferentes dimensiones de desarrollo como ser pobreza, educación, economía, empleo, ingreso, igualdad y equidad de género tienen marcada desigualdad territorial, donde los promedios nacionales ocultan las brechas existentes en el tiempo (RIMISP, 2012; RIMISP, 2015).

La desigualdad por zona geográfica pone a las mujeres rurales en una situación poco favorable, debido a que tienen menos acceso a los recursos productivos, donde disminuyen las posibilidades de obtener ingresos autónomos agropecuarios (RIMISP, 2012). Cabe destacar que, si bien algunos indicadores como los años de estudio disminuyeron la brecha e inclusive 
favorecieron a las mujeres superando la formación de los hombres, el acceso laboral y los ingresos sigue siendo desigualdad en favor de los hombres (Campos, 2016).

\section{La relación Agricultura, empleo, género y pobreza}

Deacuerdo con los datos provenientes de la Encuesta Permanente de Hogares (EPH) (DGEEC, 2018), la población paraguaya se distribuye de manera similar entre hombres y mujeres, de los 6.971.229 habitantes, el 5o,4\% son hombres y el 49,6\% son mujeres, en cuanto a la distribución por áreas de residencia el $62 \%$ de la población reside en el área urbana y el $38 \%$ en el área rural. La estructura por edades revela una población predominantemente joven, el $57,0 \%$ tiene menos de 30 años y solo el $6,4 \%$ tiene 65 años y más de edad.

Como bien se observa en la Tabla 2, el empleo rural se caracteriza por un importante porcentaje de la población en empleos familiares no remunerados, en especial en el caso de las mujeres, es así que, de cada 10 mujeres rurales ocupadas, 2 son trabajadoras familiares no remuneradas (Tabla 2).

Esta ocupación familiar no remunerada contribuye de alguna manera a aumentar la situación de pobreza de numerosas familias rurales, y restringe en consecuencia, las oportunidades para el acceso a servicios de salud y educación, que son fundamentales para mejorar la calidad de la mano de obra.

La agricultura y la ganadería son los principales motores de la economía paraguaya, según el último informe del Banco Central del Paraguay (BCP), el sector primario participa del 10,5\% del Producto Interno Bruto (PIB), el secundario del $33,6 \%$, el sector servicios del $48,5 \%$ y los impuestos a los productos representan el $7,5 \%$ (BCP, 2019).

Con el fin de obtener una aproximación de la distribución de la tierra por género a partir de datos del Censo Agrario Nacional (CAN), la información hace suponer que, dadas las normas de género prevalecientes, las mujeres que se declaran agricultoras principales de una finca propiasondehecholaspropietarias. En otras palabras, dada la construcción social de género mediante la cual la agricultura se considera una actividad masculina, tomado de las brechas de género en la propiedad de la tierra y conceptualizado por Deere y León (1982) sobre el problema general de la subestimación de la participación de las mujeres en los censos agropecuarios de Latinoamérica, se debe suponer que pocas mujeres al responder el cuestionario del censo se declaran como agriculturas principales a menos que en realidad sean las propietarias y/o jefas de familia y que no exista un hombre adulto residente en el hogar.

Tabla 2. Ocupados en el área rural por categoría y sexo (\%) en Paraguay. Año 2018

\begin{tabular}{lccc}
\hline \multicolumn{1}{c}{ Categoría de Ocupación } & Hombres & Mujeres & Total \\
\hline Empleado/obrero público & $4 \%$ & $7 \%$ & $5 \%$ \\
Empleado/obrero privado & $35 \%$ & $14 \%$ & $27 \%$ \\
Empleador o patrón & $5 \%$ & $2 \%$ & $4 \%$ \\
Trabajador por cuenta propia & $43 \%$ & $37 \%$ & $41 \%$ \\
Trabajador familiar no remunerado & $11 \%$ & $24 \%$ & $16 \%$ \\
Empleado Doméstico & $1 \%$ & $16 \%$ & $6 \%$ \\
\hline Total & $\mathbf{1 0 0} \%$ & $\mathbf{1 0 0} \%$ & $\mathbf{1 0 0} \%$ \\
\hline
\end{tabular}

Fuente: elaboración propia en base a datos de la Encuesta Permanente de Hogares de Paraguay (DGEEC, 2018). 
Tabla 3. Cantidad y Superficie de Fincas Agropecuarias hasta 50 hectáreas (Has) en Paraguay. Año 2008

\begin{tabular}{lcc}
\hline & $\begin{array}{c}\text { Total de Fincas de la } \\
\text { Agricultura Familiar (Has) }\end{array}$ & $\begin{array}{c}\text { Superficie total de fincas } \\
\text { agropecuarias (Has) }\end{array}$ \\
\hline De 1 a menos de 5 ha & 98.871 & 218.705 \\
De 5 a menos de 10 ha & 65.331 & 408.256 \\
De 10 a menos de 20 ha & 57.533 & 681.438 \\
De 20 a menos de 50 ha & $\mathbf{2 4 . 2 3 3}$ & 688.385 \\
Total, AF & $\mathbf{2 4 5 . 9 6 8}$ & $\mathbf{1 . 9 9 6 . 7 8 4}$ \\
\hline
\end{tabular}

Fuente: elaboración propia en base a datos del Censo Agrícola Nacional (MAG, 2008).

En Paraguay, de acuerdo a la Tabla 3, existen alrededor de 289.649 fincas, de las cuales 245.968 son fincas correspondientes a la Agricultura Familiar con una extensión de aproximadamente $\mathbf{1 . 9 9 6 . 7 8 4}$ hectáreas y representan el 6,4\% de la superficie total agrícola (MAG, 2008). Un gran porcentaje de los miembros de la agricultura familiar se encuentra bajo situación de pobreza o desnutrición debido a la falta de acceso a bienes públicos (infraestructura, telecomunicaciones, servicios básicos, educación, salud y otros), factores productivos (innovación, tecnología, crédito y tierra) y acceso a mercados.

Las mujeres son una de las piedras angulares dela economía rural, especialmente en los países en desarrollo. Sin embargo, en comparación con los hombres, sólo obtienen una pequeña fracción de la tierra, del crédito, de los insumos (como semillas mejoradas y fertilizantes) y de la formación e información agrícola que ellos reciben.

La ausencia de datos sobre la situación de las mujeres en cuanto al acceso y control de la tierra y los recursos productivos es una de las carencias que dificulta incorporar las cuestiones de género a las políticas y proyectos de desarrollo agrícola. En realidad, no se conoce con precisión cuántas de las mujeres que trabajan en la producción agropecuaria disponen de tierra

Figura 3. Porcentaje de Participación en explotaciones agropecuarias en Paraguay, según sexo (Has). Año 2008

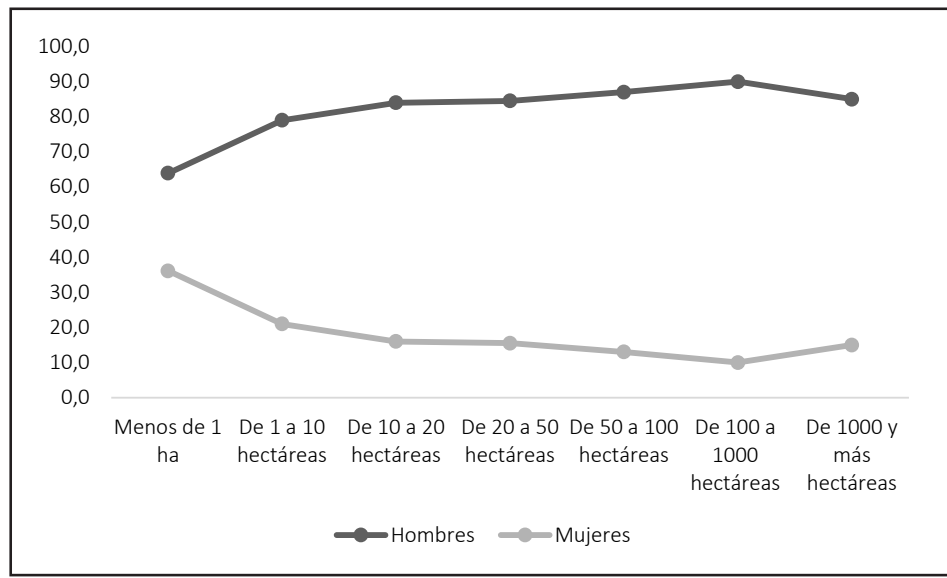

Fuente: Elaboración propia en base a datos del Censo Agrícola Nacional (MAG, 2008). 
Ayala \& Achinelli. Género y economía. Visibilización de la contribución de las mujeres en la agricultura familiar campesina en Paraguay. Año 2019

Tabla 4. Superficie cultivada por tipo de cultivo y sexo en la agricultura familiar en Paraguay (Has). Año 2008

\begin{tabular}{cccc}
\hline Superficie Total Cultivada Has & Hombres & Mujeres & Total \\
\hline Cultivos Temporales & 471.840 & 409.937 & 881.777 \\
Huerta comercial & 1.859 & 1.472 & 3.331 \\
\hline Cultivos Permanentes & 23.267 & 20.183 & 43.450
\end{tabular}

Fuente: elaboración propia en base a datos del Censo Agrícola Nacional (MAG, 2008).

propia, ni tampoco qué proporción de la tierra productiva está en manos de mujeres. En la Figura 3 se observa que cuando se trata de explotación agropecuaria las mujeres se encuentran en mayor desventaja que los hombres, en el estrato de menos de una hectárea las mujeres representan el $36,1 \%$ de los productores, mientras que su participación se reduce al $15 \%$ en las de más de 1.000 hectáreas.

Dentro de la Agricultura Familiar, las familias desarrollan diferentes tipos de cultivo dependiendo de aspectos referentes al clima, la demanda de productos y la disponibilidad de recursos económicos para el cultivo, el MAG los clasifica en cultivos temporales, huertas comerciales y cultivos permanentes, por lo que la Tabla 4 indica que 881.777 hectáreas pertenecientes a la AF son cultivos temporales, 43.450 has son cultivos permanentes y 3.331 hectáreas son huertas comerciales.

Paulatinamente, las mujeres van ganando terreno en la participación activa en actividades pecuarias y agrícolas, especialmente cuando la parcela y la vivienda queda cerca o en el mismo lugar ya que ellas deben conciliar la vida productiva con la reproductiva. Realizan tareas tales como el cuidado del ganado, de aves, la

Tabla 5. Porcentaje de la población de 14 y más años de edad que realiza actividades no remuneradas y promedio de horas semanales por sexo según tipo de actividad, Año 2016

\begin{tabular}{|c|c|c|c|c|c|c|c|c|}
\hline \multirow{2}{*}{$\begin{array}{l}\text { Actividades } \\
\text { que componen } \\
\text { al trabajo no } \\
\text { remunerado }\end{array}$} & \multicolumn{2}{|c|}{ Total } & \multicolumn{2}{|c|}{ Hombres } & \multicolumn{2}{|c|}{ Mujeres } & \multicolumn{2}{|c|}{$\begin{array}{l}\text { Diferencia Hombres- } \\
\text { Mujeres }\end{array}$} \\
\hline & $\begin{array}{l}\text { Porcentaje de } \\
\text { realización }\end{array}$ & $\begin{array}{c}\text { Promedio } \\
\text { de horas } \\
\text { semanales }\end{array}$ & $\begin{array}{l}\text { Porcentaje de } \\
\text { realización }\end{array}$ & $\begin{array}{c}\text { Promedio } \\
\text { de horas } \\
\text { semanales }\end{array}$ & $\begin{array}{c}\text { Porcentaje de } \\
\text { realización }\end{array}$ & $\begin{array}{c}\text { Promedio } \\
\text { de horas } \\
\text { semanales }\end{array}$ & $\begin{array}{l}\text { Porcentaje de } \\
\text { realización }\end{array}$ & $\begin{array}{c}\text { Promedio } \\
\text { de horas } \\
\text { semanales }\end{array}$ \\
\hline $\begin{array}{l}\text { Total } \\
\text { trabajo no } \\
\text { remunerado }\end{array}$ & $89,5 \%$ & 21,2 & $85,1 \%$ & 12,9 & $93,9 \%$ & 28,7 & $-8,8 \%$ & $-15,8$ \\
\hline $\begin{array}{l}\text { Trabajo } \\
\text { Doméstico }\end{array}$ & $82,3 \%$ & 12,6 & $72,9 \%$ & 5,3 & $91,6 \%$ & 18,3 & $-18,7 \%$ & $-13,0$ \\
\hline $\begin{array}{l}\text { Actividades } \\
\text { para otros } \\
\text { hogares y la } \\
\text { comunidad }\end{array}$ & $8,1 \%$ & 7,3 & $6,3 \%$ & 5,1 & $9,9 \%$ & 8,7 & $-3,6 \%$ & $-3,6$ \\
\hline $\begin{array}{l}\text { Cuidado a } \\
\text { Miembros del } \\
\text { Hogar }\end{array}$ & $50,0 \%$ & 10,6 & $42,9 \%$ & 7,5 & $57,1 \%$ & 12,9 & $-14,2 \%$ & $-5,4$ \\
\hline $\begin{array}{l}\text { Actividades } \\
\text { agropecuarias } \\
\text { para } \\
\text { Autoconsumo }\end{array}$ & $30,3 \%$ & 9,2 & $27,1 \%$ & 13,2 & $33,5 \%$ & 6,0 & $-6,4 \%$ & 7,2 \\
\hline
\end{tabular}


Tabla 6. Porcentaje de la población de 14 y más años de edad que realiza actividades de cuidado a miembros del Hogar y promedio de horas semanales por sexo, según indicadores, Año 2016

\begin{tabular}{|c|c|c|c|c|c|c|c|c|}
\hline \multirow[b]{2}{*}{ Indicadores } & \multicolumn{2}{|c|}{ Total } & \multicolumn{2}{|c|}{ Hombres } & \multicolumn{2}{|c|}{ Mujeres } & \multicolumn{2}{|c|}{$\begin{array}{l}\text { Diferencia Hombres- } \\
\text { Mujeres }\end{array}$} \\
\hline & $\begin{array}{l}\text { Porcentaje de } \\
\text { realización }\end{array}$ & $\begin{array}{l}\text { Promedio } \\
\text { de horas } \\
\text { semanales }\end{array}$ & $\begin{array}{l}\text { Porcentaje de } \\
\text { realización }\end{array}$ & $\begin{array}{l}\text { Promedio } \\
\text { de horas } \\
\text { semanales }\end{array}$ & $\begin{array}{l}\text { Porcentaje de } \\
\text { realización }\end{array}$ & $\begin{array}{l}\text { Promedio } \\
\text { de horas } \\
\text { semanales }\end{array}$ & $\begin{array}{l}\text { Porcentaje de } \\
\text { realización }\end{array}$ & $\begin{array}{c}\text { Promedio } \\
\text { de horas } \\
\text { semanales }\end{array}$ \\
\hline $\begin{array}{l}\text { Trabajo } \\
\text { Cuidado a } \\
\text { miembros } \\
\text { del hogar }\end{array}$ & $50,0 \%$ & 10,6 & $42,9 \%$ & 7,5 & $57,1 \%$ & 12,9 & $-14,2 \%$ & $-5,4$ \\
\hline \multicolumn{9}{|c|}{ Presencia de niños de o a 4 años de edad } \\
\hline $\begin{array}{c}\text { Sin presencia } \\
\text { de o a } 4 \text { años } \\
\text { de edad }\end{array}$ & $37,0 \%$ & 8,2 & $31,4 \%$ & 6,2 & $42,8 \%$ & 9,7 & $-11,4 \%$ & $-3,5$ \\
\hline $\begin{array}{c}\text { Con presencia } \\
\text { de o a } 4 \text { años } \\
\text { de edad }\end{array}$ & $80,9 \%$ & 13,2 & $72,5 \%$ & 9,0 & $88,3 \%$ & 16,3 & $-15,8 \%$ & $-7,3$ \\
\hline \multicolumn{9}{|c|}{ Presencia de personas de 65 años y más de edad } \\
\hline $\begin{array}{l}\text { Sin presencia } \\
\text { de } 65 \text { años y } \\
\text { más de edad }\end{array}$ & $55,7 \%$ & 10,7 & $48,2 \%$ & 7,6 & $63,2 \%$ & 13,0 & $-15,0 \%$ & $-5,5$ \\
\hline $\begin{array}{l}\text { Con presencia } \\
\text { de } 65 \text { años y } \\
\text { más de edad }\end{array}$ & $33,5 \%$ & 10,3 & $26,8 \%$ & 7,3 & $39,7 \%$ & 12,2 & $-12,9 \%$ & $-5,0$ \\
\hline \multicolumn{9}{|c|}{ Jefatura } \\
\hline Jefe & $51,0 \%$ & 9,8 & $50,2 \%$ & 8,4 & $52,8 \%$ & 12,6 & $-2,6 \%$ & $-4,2$ \\
\hline No Jefe & $49,5 \%$ & 11,1 & $36,1 \%$ & 6,4 & $58,4 \%$ & 13,0 & $-22,3 \%$ & $-6,6$ \\
\hline \multicolumn{9}{|c|}{ Estado civil } \\
\hline $\begin{array}{l}\text { Unido/ } \\
\text { Casado }\end{array}$ & $60,8 \%$ & 11,7 & $55,2 \%$ & 8,3 & $66,2 \%$ & 14,5 & $-10,9 \%$ & $-6,2$ \\
\hline Resto $(*)$ & $36,5 \%$ & 8,2 & $27,7 \%$ & 5,6 & $45,4 \%$ & 9,8 & $-17,7 \%$ & $-4,2$ \\
\hline
\end{tabular}

Fuente: Elaboración propia en base a datos de la Encuesta de Uso del tiempo del 2016 (DGEEC, 2016).

cría y el cuidado de animales menores, la recolección y selección de granos, entre otros. El principal problema que atraviesan las mujeres paraguayas en general y las mujeres rurales en particular, es que por lo general sus actividades no son remuneradas y se desarrollan en contextos de pobreza, lo que se convierte en una barrera para lograr la autonomía económica. Otro aspecto para destacar es la imposibilidad que tienen las mujeres de conciliar la vida productiva con la reproductiva, pues casi toda la carga de cuidados al interior de los hogares las llevan ellas (Tabla 5 y 6 )

Además, según se puede observar en la Tabla 4, Tabla 5 y Tabla 6; se encargan de comprar los insumos, cuidar del huerto familiar y cuentan con un importante protagonismo en tareas de cosecha y postcosecha tales como acarreo, clasificación, acopio y transformación de alimentos.

\subsection{Mujeres rurales, derechos y autonomía económica}

En Paraguay viven aproximadamente 849.887 mujeres rurales de 15 años y más en edad de trabajar (48,0 \% de la población rural total de ese rango de edad), que con su trabajo en su mayoría invisibilizado 
Ayala \& Achinelli. Género y economía. Visibilización de la contribución de las mujeres en la agricultura familiar campesina en Paraguay. Año 2019

Tabla 7. Porcentaje de la población de 14 y más años de edad que realiza actividades de cuidado a miembros del Hogar y promedio de horas semanales por sexo, según indicadores, Año 2016

\begin{tabular}{|c|c|c|c|c|c|c|c|c|}
\hline \multirow{2}{*}{$\begin{array}{c}\text { Área de } \\
\text { residencia }\end{array}$} & \multicolumn{2}{|c|}{ Total } & \multicolumn{2}{|c|}{ Hombres } & \multicolumn{2}{|c|}{ Mujeres } & \multicolumn{2}{|c|}{$\begin{array}{l}\text { Diferencia Hombres- } \\
\text { Mujeres }\end{array}$} \\
\hline & $\begin{array}{c}\text { Porcentaje } \\
\text { de } \\
\text { realización }\end{array}$ & $\begin{array}{c}\text { Promedio } \\
\text { de horas } \\
\text { semanales }\end{array}$ & $\begin{array}{c}\text { Porcentaje } \\
\text { de } \\
\text { realización }\end{array}$ & $\begin{array}{c}\text { Promedio } \\
\text { de horas } \\
\text { semanales }\end{array}$ & $\begin{array}{l}\text { Porcentaje } \\
\text { de } \\
\text { realización }\end{array}$ & $\begin{array}{c}\text { Promedio } \\
\text { de horas } \\
\text { semanales }\end{array}$ & $\begin{array}{c}\text { Porcentaje } \\
\text { de } \\
\text { realización }\end{array}$ & $\begin{array}{c}\text { Promedio } \\
\text { de horas } \\
\text { semanales }\end{array}$ \\
\hline Total País & $2,3 \%$ & 14,4 & $1,6 \%$ & 9,9 & $3,0 \%$ & 16,8 & $1,4 \%$ & 6,9 \\
\hline Área Urbana & $2,3 \%$ & 15,9 & $1,6 \%$ & 12,0 & $3,1 \%$ & 17,8 & $1,5 \%$ & 5,8 \\
\hline Área Rural & $2,2 \%$ & 11,8 & $1,5 \%$ & 6,3 & $2,8 \%$ & 15,0 & $1,3 \%$ & 8,7 \\
\hline
\end{tabular}

Fuente: Elaboración propia en base a datos de la Encuesta de Uso del tiempo del 2016 (DGEEC, 2016).

sostienen a sus hogares y a la comunidad.

Según Arzate (2004), el lugar que adquieren las mujeres pobres en los discursos dominantes del desarrollo, proviene de los estudios que denuncian un fenómeno llamado feminización de la pobreza. Éste alude tanto a la desproporcionada representación de las mujeres entre los pobres comparada con la de los hombres, como a las características que asume la pobreza entre las mujeres, el periodo que permanecen en esta situación, las dificultades para superarla y los efectos de los demás miembros del grupo doméstico familiar.

Las zonas rurales por lo general presentan características mucho más marcadas en cuanto a la desigualdad y vulnerabilidad que las zonas urbanas; el acceso a servicios básicos para desarrollar una vida digna es sustancialmente desigual, por lo que generalmente es mucho más difícil acceder a buena calidad educativa y sanitaria y si bien estas condiciones limitan el desarrollo integral de las poblaciones rurales (hombres y mujeres), cuando esto se traduce en condición de pobreza de la población, los datos muestran que las mujeres rurales se encuentran en situaciones de mayor vulnerabilidad que los hombres rurales. De acuerdo a la figura 4 , el $23,0 \%$ de las mujeres se encuentra en situación de pobreza y el $8,7 \%$ en condición de pobreza extrema².

Si bien ha habido avances en el reconocimiento y exigibilidad de los derechos de las mujeres, estas todavía se encuentran en desventaja social por el simple hecho de ser mujeres, sobre todo en cuanto al derecho a la educación, salud, una vida libre de violencia, acceso al trabajo digno y decente, participación política y toma de decisiones, derechos a la salud sexual y reproductiva.

La situación de las mujeres rurales dedicadas a la agricultura familiar presenta grandes dificultades por el hecho que aún no se ha llegado al pleno reconocimiento como personas sujetas de derechos, lo que se materializa en el poco acceso de las mujeres a la tenencia de la tierra, lo que limita sus posibilidades de generar recursos propios, garantizando así la autonomía económica de las mujeres rurales, entendiéndose esta como su capacidad para ser proveedoras de su propio sustento, así como el de las personas que de ellas dependen. En ese sentido, la autonomía económica es más que autonomía financiera, ya que también incluye el acceso a la seguridad social y a los servicios públicos (FAO, 2013).

De acuerdo a la Tabla 8, el 52,4 \% de

\footnotetext{
2 La pobreza corresponde a la población con un ingreso inferior a la Línea Total (Canasta Básica de Alimentos y no Alimentos), por tanto, incluye a los pobres extremos y pobres no extremos y la pobreza extrema corresponde a la población con un ingreso inferior a la Línea de Pobreza Extrema (Canasta Básica de Alimentos).
} 
Figura 4. Principales actividades de los ocupados en el área rural por sexo en Paraguay. Año 2018

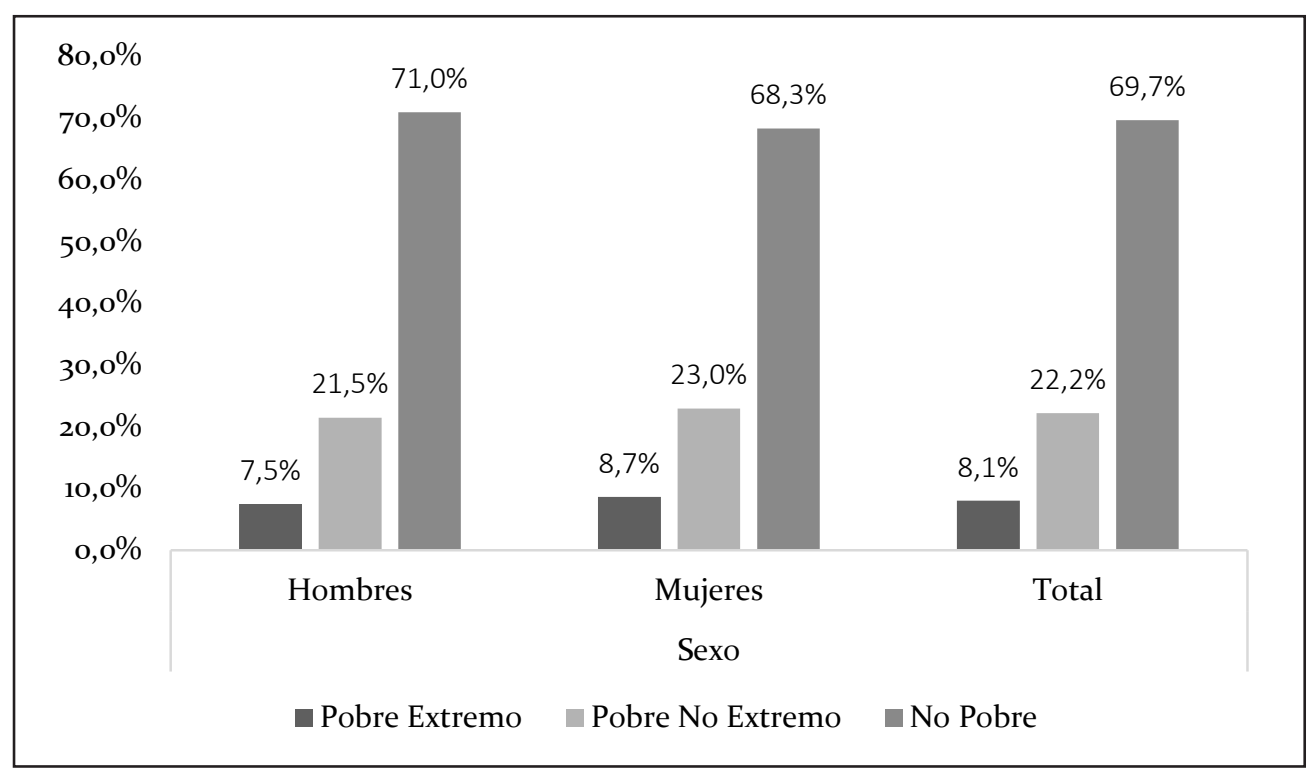

Fuente: Elaboración propia en base a datos del Censo Agrícola Nacional (MAG, 2008).

las mujeres rurales activas de 15 años y más, está ocupada, el 44,3\% está inactiva y el 3,4\% está desocupada, el dato resaltante es la gran proporción de mujeres que se encuentran inactivas, 4 de cada 10 mujeres en edad de trabajar se encuentra en esta situación.

Las principales razones por las que las mujeres están inactivas son: realizar labores del hogar, ser estudiantes y motivos familiares, dando cuenta esto que las mujeres rurales en gran medida no pueden conciliar la vida productiva y reproductiva en un contexto de mercado laboral fuera del hogar, por tanto, encuentran en la actividad agrícola una opción válida pues esta se desarrolla en gran medida dentro de sus fincas o en las de sus familias, pudiendo así realizar actividades para su sustento y cuidar de su familia al mismo tiempo (Tabla 9).

En cuantoa las principales actividades desarrolladas tanto por hombres como por mujeres en el área rural se destacan las actividades relacionadas con la agricultura y la ganadería, en el caso de las mujeres de 15 años y más de edad, 4 de cada 10 se dedica a actividades agropecuarias y como ya se ha observado en la tabla 1, la mayor parte de los ocupados en el área rural son trabajadores por cuenta propia (Figura 5).

Tabla 8. Población Activa en el área rural por Sexo (\%) en Paraguay. Año 2018

\begin{tabular}{cccc}
\hline Población Activa & Hombres & Mujeres & Total \\
\hline Ocupados & $84,8 \%$ & $52,4 \%$ & $69,2 \%$ \\
Desocupados & $2,5 \%$ & $3,4 \%$ & $2,9 \%$ \\
Inactivos & $12,7 \%$ & $44,3 \%$ & $27,8 \%$ \\
\hline Total & $\mathbf{1 0 0 , 0} \%$ & $\mathbf{1 0 0 , 0} \%$ & $\mathbf{1 0 0 , 0} \%$ \\
\hline
\end{tabular}

Fuente: elaboración propia en base a datos de la Encuesta Permanente de Hogares (DGEEC, 2018). 
Ayala \& Achinelli. Género y economía. Visibilización de la contribución de las mujeres en la agricultura familiar campesina en Paraguay. Año 2019

Tabla 9. Razones de Inactividad de las mujeres rurales en Paraguay (\%). Año 2018

\begin{tabular}{lc}
\hline \multicolumn{1}{c}{ Razones de inactividad } & $\%$ \\
\hline Estudiantes & 16,4 \\
Labores del Hogar & 44,1 \\
No consigue trabajo & 5,3 \\
Enferma & 6,1 \\
Anciana & 6,5 \\
Discapacitada & 2,6 \\
Motivos Familiares & 16,2 \\
Otra situación & 2,1 \\
\hline Total & 100,0 \\
\hline
\end{tabular}

Fuente: elaboración propia en base a datos de la Encuesta Permanente de Hogares (DGEEC, 2018).

Figura 5. Distribución del Ingreso Rural de la población ocupada por Sexo en Paraguay. Año 2018

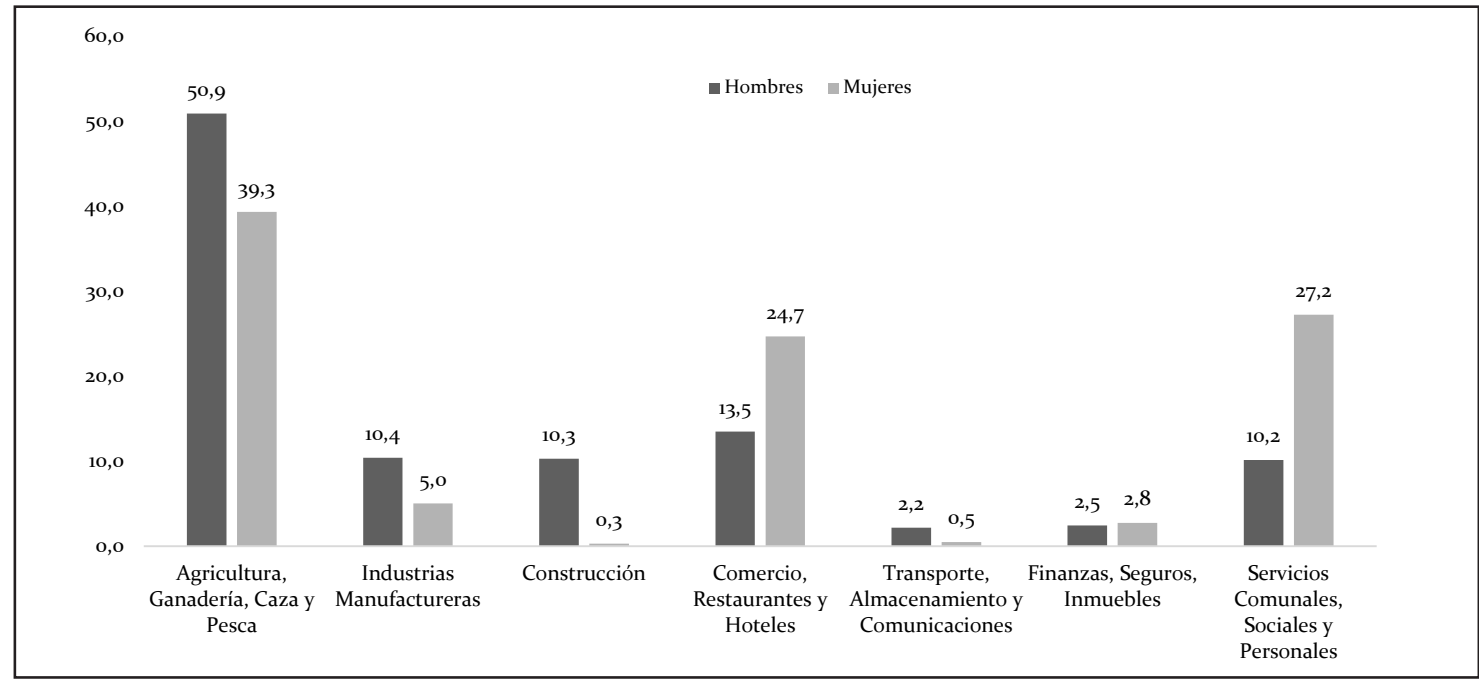

Fuente: Elaboración propia en base a datos e la Encuesta Permanente de Hogares (DGEEC, 2018).

En la Figura 6 se puede observar que los ingresos rurales tienen sesgo hacia la izquierda, lo que significa que tienen asimetría negativa, pero el ingreso de los hombres toma una dirección más notoria, lo que significa que, en comparación, los ingresos de los hombres son mayores a los ingresos de las mujeres, en otras palabras, una mayor proporción de trabajadoras rurales se concentran entre los ingresos más bajos, mientras que en el caso de los trabajadores rurales se encuentran alrededor de un ingreso más alto, lo que da cuenta de las diferencias de ingreso entre hombres y mujeres en el área rural.

\subsection{La participación de las mujeres en proyectos de fomento de la $\mathrm{AF}$}

La institución encargada de fomentar proyectos de apoyo a la Agricultura Familiar Campesina es el Ministerio de Agricultura y Ganadería (MAG) y lo hace a través de la implementación de proyectos para la creación de comités de producción, el mejoramiento del sistema de producción, incremento del ingreso familiar de los socios, aumento de la 
Figura 6. Distribución del Ingreso Rural de la población ocupada por Sexo en Paraguay. Año 2018

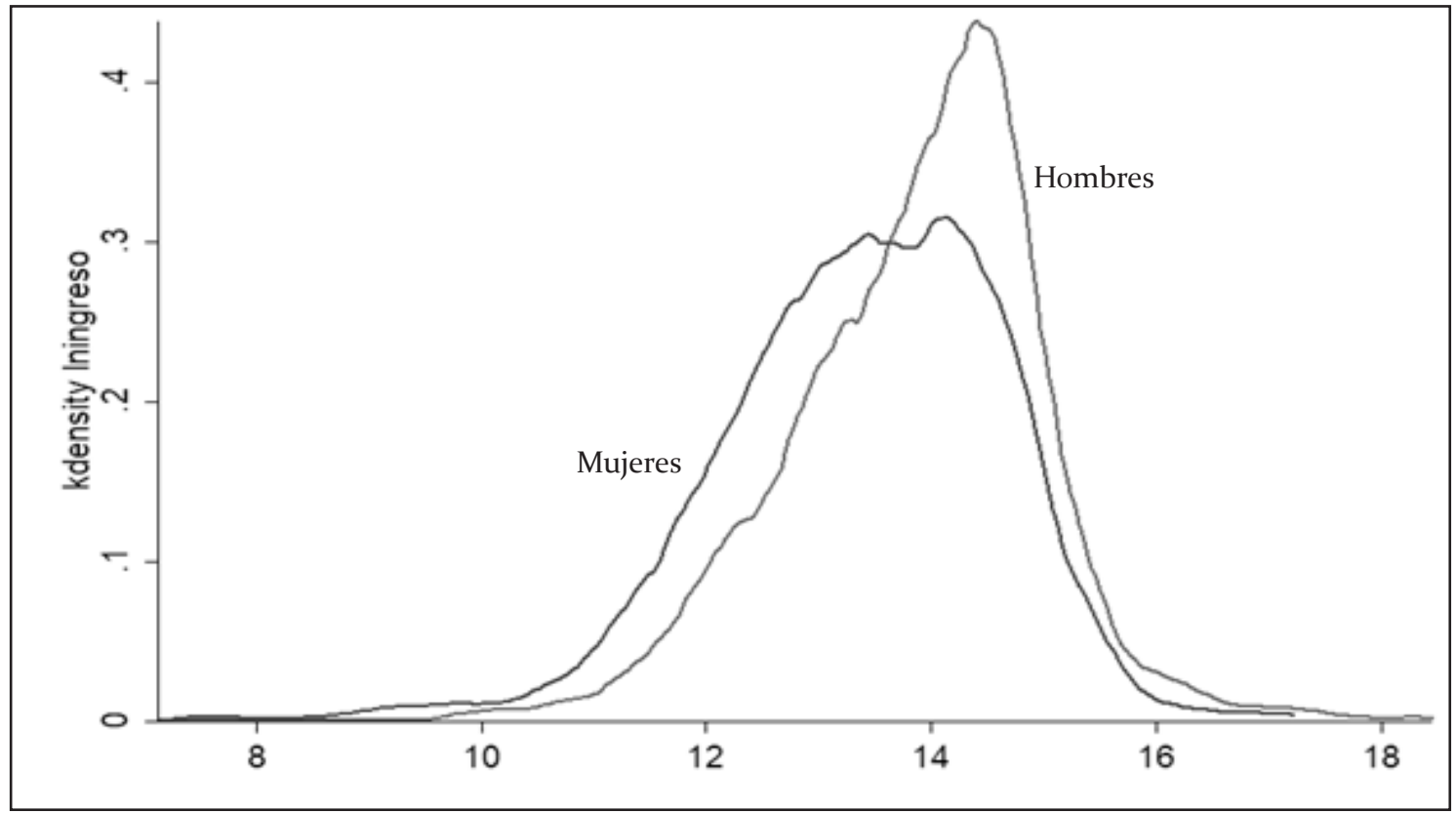

Fuente: Elaboración propia en base a datos e la Encuesta Permanente de Hogares (DGEEC, 2018).

productividad de las fincas, el apoyoa la creación de centros de acopio y equipamiento para la producción agrícola y ganadera, entre otros.

Según datos del año 2018 proveídos por la DEAg, las mujeres están involucradas en el comercio a pequeña escala a través de su participación en comités de producción y con la participación activa en la elaboración de sus planes de negocio. En cuanto al Proyecto Paraguay Inclusivo 3 (PPI), del total de 17.152 beneficiarios, el $55 \%$ son hombres y el $45 \%$ son mujeres, distribuidos en comités de producción por departamentos, en el gráfico se observa claramente la mayor participación de mujeres en los departamentos de Caaguazú, Canindeyú,

3 El Proyecto Paraguay Inclusivo (PPI) tenía como objetivo contribuir a incrementar los activos, los ingresos y calidad de vida de los agricultores familiares campesinos pobres y población rural pobre, mediante su inserción en forma sostenible, en cadenas de valor, con visión de género y conservación del medio ambiente, actualmente este proyecto está cerrado.
Guairá y Paraguarí, por otro lado, el departamento de San Pedro muestra mayor participación de hombres, además de ser el departamento con mayor cantidad de beneficiarios.

El programa PRODERS es uno de los proyectos más grandes del MAG, tiene más de 38.000 beneficiarios, de los cuales el $47,9 \%$ son hombres y el $52,1 \%$ son mujeres, los departamentos con mayor cantidad de mujeres participando en proyectos de PRODERS son: Canindeyú, Concepción y San Pedro, mientras que los departamentos con mayor participación de hombres son Caaguazú, Itapúa y Paraguarí, cabe destacar que el proyecto PRODERS tiene varios proyectos de apoyo a la agricultura familiar campesina entre los que se pueden nombrar el mejoramiento del sistema de producción orientados a la AF, incremento del ingreso familiar de los socios, aumento de la productividad de las fincas, abastecimiento de agua, desarrollo de la producción agropecuaria con infraestructura básica, 
Ayala \& Achinelli. Género y economía. Visibilización de la contribución de las mujeres en la agricultura familiar campesina en Paraguay. Año 2019

Figura 7. Participación de Hombres y Mujeres en el proyecto PPI por departamento en Paraguay (\%). Año 2018

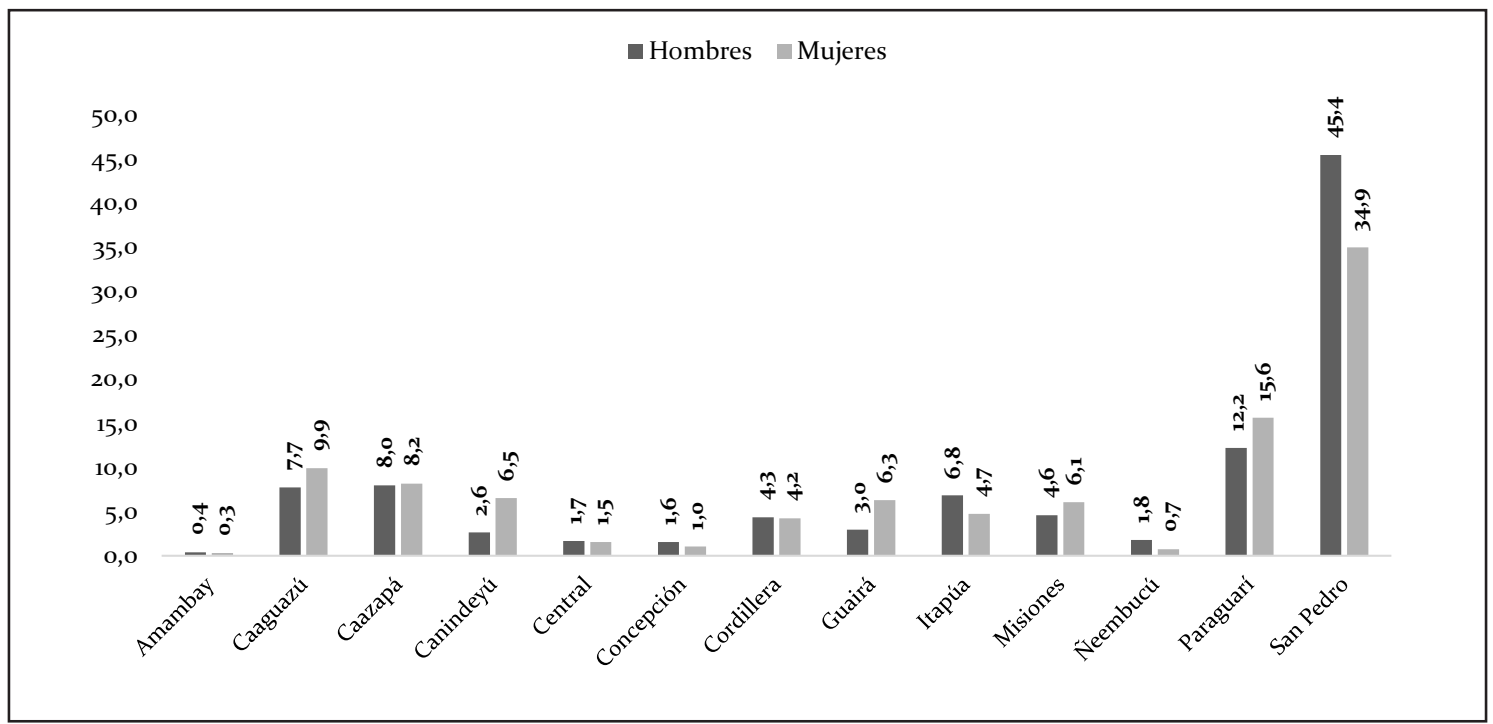

Fuente: Elaboración propia en base a datos del Censo Agrícola Nacional (MAG, 2018).

centro de acopio y equipamiento para la producción agrícola y ganadera (Figura 8 ).

En cuanto al programa nacional de Fomento de la Cadena Láctea (FCL), del mismo participan 780 pequeños productores, el 5o,3\% son hombresyel 49,7\% mujeres existiendo un equilibrio relativo

Figura 8. Participación de Hombres y Mujeres en el proyecto PRODERS por departamento en Paraguay (\%). Año 2018

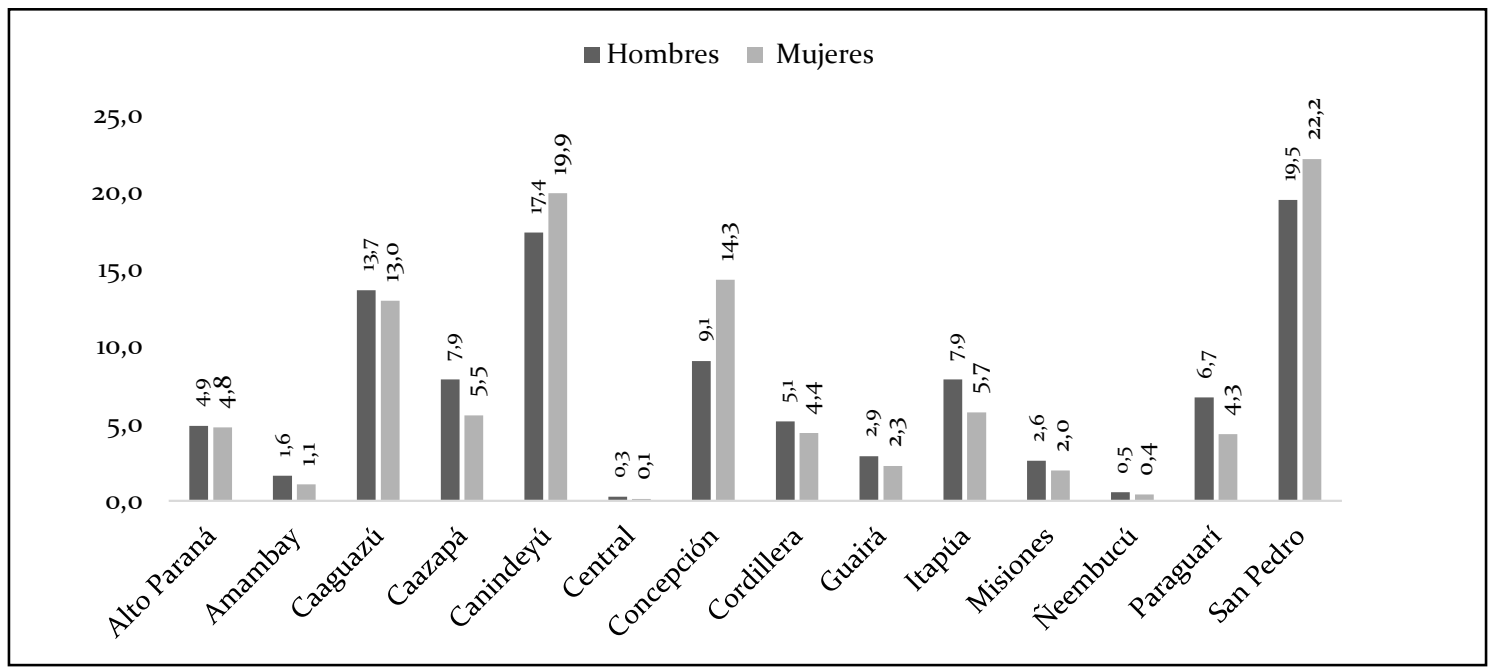

Fuente: Elaboración propia en base a datos del Censo Agrícola Nacional (MAG, 2018). 
Figura 9. Participación de Hombres y Mujeres en el proyecto FCL por departamento en Paraguay $(\%)$

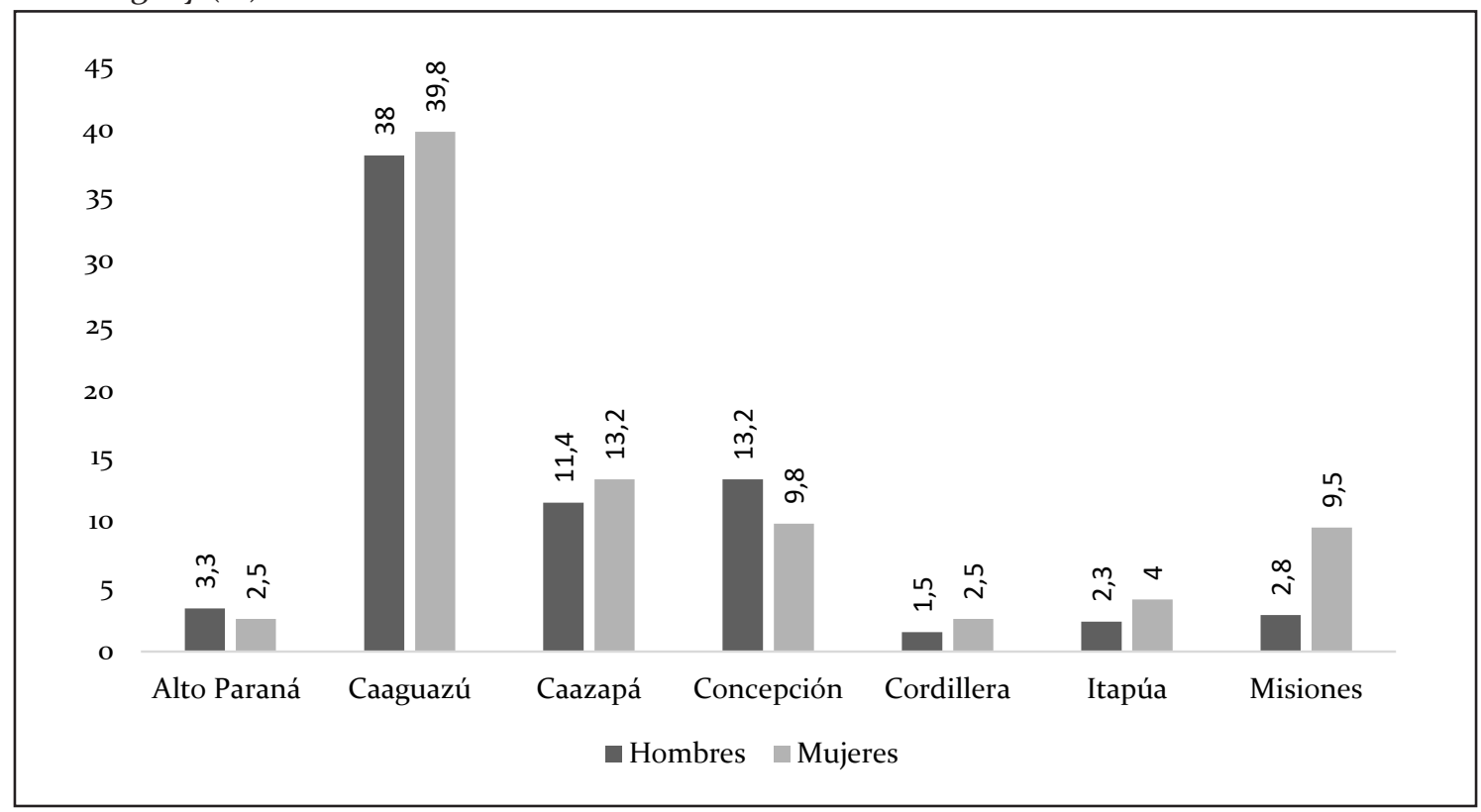

Fuente: Elaboración propia en base a datos del MAG, 2018.

entre hombres y mujeres beneficiarios, los departamentos que registran mayor participación femenina son: Caaguazú, Itapúa, Misiones y Paraguarí (Figura 9).

En cuanto al proyecto de Aumento de la Tasa de Procreo (ATP), este tiene 160 beneficiarios, el $19,6 \%$ son mujeres y el $80,3 \%$ son hombres, los departamentos con mayor participación femenina son Misiones y Paraguarí. Este proyecto tiene como objetivo principal el fortalecer el procreo bovino a favor de pequeños y medianos productores ganaderos (Figura 10).

La Necesidad del reconocimiento de la agricultura familiar con enfoque de género en la política pública

La configuración de la agricultura familiar muestra una dominación de hombres en la titulación de propiedad con respecto a las mujeres (Según el censo agropecuario del 54\% frente a 46\%).

Al heredar la propiedad, en este caso la tierra se asume también una identidad, la que centra toda la actividad en la persona. En efecto, la herencia del establecimiento comienza con la designación de un sucesor, el que habitualmente es varón (Gallo y Peluso, 2013). A pesar de esta modalidad de formación, de enseñar en el gusto por la tarea de campo, no siempre los jóvenes optan por continuar el proyecto familiar. Esta es, sin duda, una de las principales preocupaciones, ya que aún no se considera plenamente a la mujer como potenciadora de la producción y comercialización en la $\mathrm{AF}$, más aún al no tener la propiedad de la tierra como el bien principal para la producción obstaculiza sus posibilidades de desarrollar el proyecto de la pequeña agricultura pues tienen limitado el financiamiento económico.

La pertinencia de la política pública a favor de la producción familiar está centrada primero en disminuir la desigualdad del acceso a la tierra, dónde Paraguay es un país muy desigual. En segundo lugar, por lo que la política debe sostenerse en un enfoque de justicia social que busque la sustentabilidad de la producción familiar como alternativa a los procesos de expansión del capitalismo agrario y el fomento de la agricultura familiar con visión de género con mayores 
Figura 10. Participación de Hombres y Mujeres en el proyecto ATP por departamento en Paraguay (\%). Año 2018

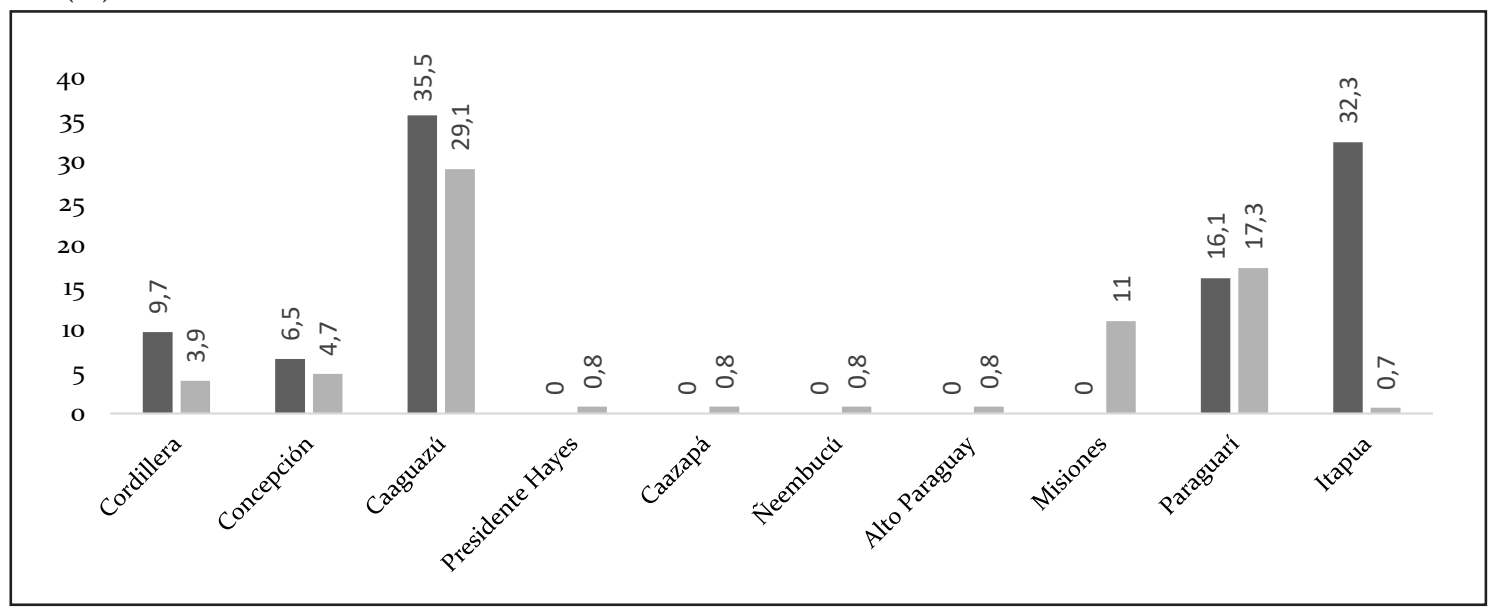

Fuente: Elaboración propia en base a datos del MAG (2018).

oportunidades para las mujeres rurales.

La idea debe centrarse en la transversalización de políticas con el fin de llevar de manera rápida y económica el Estado a todos los rincones de los territorios rurales, buscando proponer a las poblaciones rurales la capacidad paulatina de diseñar su propio futuro.

En la misma generación de política debe considerarse las normativas ambientales globales de cuidado del ambiente, de promoción de la seguridad alimentaria, aspectos sobre uso, manejo y conservación del suelo, planificación sobre el uso del agua, conformación de comités de producción, elaboración de planes de negocio, acceso al crédito y asesoramiento tecnológico.

Si bien Paraguay ha avanzado en la compra y distribución de tierras a productores familiares en situación de pobreza en zonas rurales, el desafío es aún grande en términos de distribución colectiva.

En cuanto al apoyo financiero, el MAG cuenta con una serie de programas que fomentan la elaboración de planes de negocios agrícolas y posterior financiamiento a aquellas actividades típicas de la agricultura familiar, como la producción fruti-hortícola, la producción lechera, entre otros.

Se debe contemplar la tenencia de seguro agrícola para hacer frente a cualquier contingente que pueda surgir, en especial para una agricultura aún muy dependiente del clima.

Promover la existencia de un programa de microcrédito para proporcionar financiamiento a corto plazo (de hasta un año y seis meses) a mujeres productoras rurales que no acceden a las fuentes de financiamiento ofrecidas en el mercado, considerando refinanciamiento en épocas de mala cosecha, shocks climáticos, invasión de plagas, entre otros.

\section{Conclusiones}

La agricultura sigue siendo una de las principales fuentes de empleo tanto de hombres y mujeres queviven en el área rural, pese, a que en términos macroeconómicos vaya perdiendo peso, como se ha observado anteriormente en la figura 5 y en base a datos de la encuesta de hogares del año 2018 (DGEEC, 2018), el 50,9\% de hombres y el 39,3\% de mujeres tienen como actividad principal la agricultura y la ganadería.

Entre las mujeres que trabajan en la agricultura, el $41,8 \%$ lo hacen por cuenta propia y como trabajadora familiar no remunerada el 51,6\%. Los datos reflejan que 
las condiciones son de alta vulnerabilidad pues carecen de contrato, sistemas de protección social y de jubilación.

Las mujeres desempeñan un papel esencial en la economía y el bienestar de los hogares y sociedades rurales, aunque su contribución no es suficientemente reconocida ni valorada. En interminables jornadas de trabajo, asumen una gran diversidad de responsabilidades dentro y fuera del hogar que van desde el cuidado familiar hasta la participación en la producción agropecuaria o el trabajo asalariado, habitualmente en sectores con un alto grado de informalidad, como el trabajo doméstico remunerado o el pequeño comercio.

Sin duda alguna la política pública debe estar centrada en promover la igualdad de género en todos los ámbitos del desarrollo de las personas y en especial en la agricultura familiar considerándola como la base de la seguridad alimentaria de los pueblos.

Las políticas públicas de fomento de la AF deben tener el rol primordial de reducir las brechas de género a través de una mayor provisión de oportunidades a las mujeres rurales para lograr acceso a mercados e información, asistir a las mujeres productoras en la compra de insumos para su producción, aumentar el rol de las mujeres en puestos de poder y liderazgo, generar vínculos que favorezcan la participación empresarial de las mujeres y principalmente en el reconocimiento de su trabajo como cuidadoras del hogar y como pequeñas productoras.

Ese poco reconocimiento de la mujer como protagonista de la Agricultura Familiar muchas veces es socavada por la falta de indicadores de género para medir el uso de los recursos, el acceso a ellos y la distribución de las responsabilidades entre los hombres y las mujeres a lo largo de la cadena de producción, lo cual podría ayudar a detectar brechas de género. Esto, sin duda, contribuiría al desarrollo de acciones dirigidas a mejorar sustancialmente la equidad y la igualdad de género en la
Agricultura Familiar, y, por ende, incidiría en una mayor dinamización de la economía.

Definitivamente, contar con una visión del desarrollo y el diseño políticas paliativas y emergentes es insuficiente pues sólo permite ver el corto plazo sin lograr realmente modificar el problema de origen (concentración de la tierra y la riqueza, mala distribución del ingreso, falta de enfoque de género en las políticas agropecuarias), las limitaciones que impone una visión paliativa y emergente basada en modelos neoliberales no frenaran las desigualdades de género, las desigualdades salariales, la pobreza y el deterioro ambiental, más bien este artículo vislumbra a través de los datos una persistencia y profundización de las desigualdades sociales.

El gran problema que también subyace es que las políticas de desarrollo productivo no se desarrollan en espacios de debate y reflexión sobre los cambios en las dimensiones subjetivas de la vida de las mujeres rurales cuando son receptoras de las transferencias y corresponsables del éxito de un programa. Por el contrario, el estatus social que se les da a las mujeres campesinas en estos programas, no sólo vuelve a colocarlas en los roles tradicionales de la división sexual del trabajo, sino que además son sometidas a las nuevas relaciones impuestas por las instituciones al adquirir otras responsabilidades con el Estado mediante sus programas. Todo ello imposibilita las posibilidades de que las mujeres sean reconocidas como actoras sociales, obteniendo así el rol ideal para el logro de su empoderamiento; es decir, del acceso al poder por la vía de la autonomía, libertad, autoafirmación y reconocimiento.

\section{Referencias}

Arzate, J. (2004). Pobreza extrema en México, evaluación microsociología, Universidad Autónoma del Estado de México. Ediciones Gernika.

Banco Central del Paraguay, BCP. (2019). Sistema de Cuentas Nacionales del Paraguay. Análisis del PIB. BCP : https://www.bcp.gov.py/cuentas- 
nacionales-anuales-i406

Benería, L., \& Sen, G. (1981). Accumulation, reproduction, and Women's Role in Economic Development: Boserup Revisited. Signs. Journal of Women in Culture and Society, 7(2): 279-298.

Kempf, B., Wedig, R., \& Carine, J. (2019). Processos de resistência de mulheres camponesas: olhares pela perspectiva decolonial / Resistance processes of peasant women: a look through the decolonial perspective. Universidad Nacional de La Plata. Facultad de Humanidades y Ciencias de la Educación. Centro de Historia Argentina y Americana.

Boserup, E. (1970). Women's Role in Economic Development. Martin's Press.

Campos, C. (2016). Políticas y experiencias territoriales relevantes para el empoderamiento de las mujeres rurales en Paraguay:unanálisis desde el enfoque territorial. Centro Latinoamericano para el Desarrollo Rural - ONU Mujeres: https://lac.unwomen.org/ es/digiteca/publicaciones/2017/05/ politicas-y-experiencias-territorialespara-el-empoderamiento-de-lasmujeres-rurales-en-paraguay

Carosini Ruíz Díaz, L. Barrios Leiva, O., Nakayama, H., Garcete, G., Achinelli, M., Cabral, A., Olmedo B., S., Báez, J., Morínigo, J. \& Rodríguez, A. (2020). Impacto económico de la aprobación de la soja transgénica en el Paraguay. Universidad Nacional de Asunción, Facultad de Ciencias Económicas: https://drive.google. com/file/d/1xo3NY6-kGoS-UwfY8HC_ JsC4tOG6pygx/view

Centro Latinoamericano para el Desarrollo Rural, RIMIS. (2015). Pobreza y desigualdad: informe latinoamericano 2015 - Género y territorio. RIMISP.

Centro Latinoamericano para el Desarrollo Rural, RIMISP. (2012). Territorios rurales en movimiento. Informe final Programa Dinámicas Territoriales Rurales en América Latina 2007-2012. RIMISP.
Deere, C. D., \& León, M. (1982). Women in Andean agriculture: Peasant production and rural wage employment in Colombia and Peru. International Labour Office.

Dirección General de Estadística, Encuestas y Censos, DGEEC. (2018). Resultados de la encuesta permanente de hogares (EPH). Principales indicadores de empleo e ingresos. https://www.dgeec. gov.py/microdatos/microdatos.php

Dirección General de Estadística, Encuestas y Censos, DGEEC. (2016). Principales resultados de la encuesta del uso del tiempo en Paraguay. DGEEC. https:// www.ine.gov.py/Publicaciones/ Biblioteca/eut2016/EUT2016.pdf

Dobrée, P. (2014). El derecho a la Tierra. Perspectivas para el análisis. En P. Dobrée, M. Pereira, Q. Riquelme, O. Ayala, L. Soto, \& V. Imás (Eds.), La Tierra en Paraguay: de la desigualdad al ejercicio de derechos (pp. 1-14). Programa Democratización y Construcción de la Paz - Paraguay.

Gallo, A., \& Peluso, I. (2013). Estrategias sucesorias en la ganadería familiar: un enfoque de género. Revista De Ciencias Sociales, 17-34.

Guereña, A. (2016). Kuña ha Yvy: Desigualdades de género en el acceso a la tierra en Paraguay. ONU Mujeres Paraguay, Oxfam en Paraguay: https:// www.oxfam.org/es/informes/kuna-hayvy-desigualdades-de-genero-en-elacceso-la-tierra-en-paraguay

Imas, V., Benítez, G., Serafini, V., Zavattiero, C., \& García, L. (2019). Seguridad y Soberanía Alimentaria en Paraguay. Sistema de Indicadores y Línea de Base. Asunción: Centro de Análisis y Difusión de la Economía Paraguaya. CADEP.

Kretschmer, R. (2008). Informe de Situación Tipo I. Movimiento de Jóvenes Campesinos en Paraguay. Las demandas de acceso a la tierra, educación, trabajoy recreación del Consejo Juvenil Regional de la Asociación de Agricultores del Alto Paraná (ASAGRAPA)" en la tierra en el Paraguay: de la desigualdad al ejercicio de derechos. https://www.cde. 
org.py/wp-content/uploads/2014/10/ La-tierra-en-el-Paraguay.pdf

Ministerio de Agricultura y Ganadería, MAG. (2008). Censo Agropecuario Nacional. http://www.mag.gov.py/ Censo/Book\%201.pdf

Ministerio de Agricultura y Ganadería, MAG. (2018). Datos de los programas llevados a cabo para agricultura familiar. DEAG. http://www.mag.gov. py/index.php/publicaciones

Organización de las Naciones Unidas de la Alimentación y la Agricultura, FAO. (2008). Situación de las mujeres rurales. Paraguay. ftp://ftp.fao.org/ docrep/fao/o11/a1591s/a1591s.pdf
Organización de las Naciones Unidas de la Alimentación y la Agricultura, FAO. (2013). Programa de la FAO. Equidad entre géneros. http://www. fao.org/gender/genderhome/genderprogramme/es/

Paraguay. Ley $\mathrm{N}^{\circ}$ 2419/2004, Que crea el instituto nacional de desarrollo rural y de la tierra

Programa de las Naciones Unidas para el Desarrollo, PNUD. (2010). Sector rural paraguayo: una visión general para un diálogo informado. Cuaderno de Desarrollo Humano. http://www.mag. gov.py/varias/Sector\%2oRural\%20 Paraguayo\%202010.pdf

\section{Sobre las Autoras}

Dahiana Ayala

Realiza un doctorado en Economía y Sociología del Trabajo en la Aix Marseille Université, Aixen-Provence, Francia. Máster en Políticas Públicas y Sociales por la Universidad Pompeu Fabra de Barcelona, España. Economista por la Facultad de Ciencias Económicas de la UNA. Fue docente de Economía Laboral y Metodología de la Investigación en las carreras de economía y administración en la facultad de ciencias económicas de la UNA. Se ha desempeñado como consultora para organismos nacionales e internacionales y actualmente trabaja como investigadora en el Laboratorio de Economía y Sociología del Trabajo de la Aix Marseille Université (LEST-AMU) en Aix-en-Provence, Francia.

\section{Marcela Achinelli}

Realiza un doctorado en Demografía en la Universidad de Córdoba, Argentina. Máster en Entidades de la Economía Social por la Universidad Nacional de Rosario, Argentina. Economista por la Facultad de Ciencias Económicas de la UNA (FCE-UNA). Está categorizada en Nivel I de PRONII. Es Docente en la Escuela de Economía de la FCE-UNA y sus trabajos vinculan la demografía, la economía y el género. 